\title{
Personal Protective Equipment in Health Workers during Coronavirus Disease-19 Outbreak
}

\author{
Dragan Mijakoski ${ }^{1,2 *}$, Sasho Stoleski ${ }^{1,2}$, Dragana Bislimovska ${ }^{1,2}$, Elena Pazheska-Dimitrioski ${ }^{3}$, Elizabeta Karasmanakis ${ }^{4}$, \\ Jordan Minov ${ }^{1,2}$, Jovanka Karadzinska-Bislimovska ${ }^{1,2}$ \\ ${ }^{1}$ Department of Allergy, Institute of Occupational Health of RM, Skopje, Republic of Macedonia; ${ }^{2}$ Department of Occupational \\ Medicine, Faculty of Medicine, Ss. Cyril and Methodius, University in Skopje, Skopje, Republic of Macedonia; ${ }^{3}$ Health Centre, \\ Prilep, Republic of Macedonia; ${ }^{4}$ Health Centre, Bitola, Republic of Macedonia
}

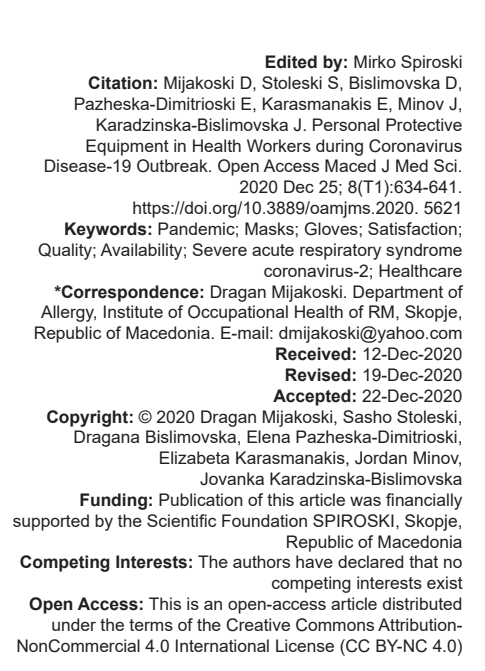

\section{Abstract}

BACKGROUND: Coronavirus (CoV) disease (COVID)-19 pandemic has put immense pressure on the healthcare systems worldwide.

AIM: The aim of the actual study was to assess the availability of personal protective equipment (PPE) in health workers (HWs) during an outbreak.

METHODS: The study was conducted in April-May 2020 using an on-line questionnaire. Completed surveys were returned by $560 \mathrm{HWs}$ (297 physicians, 79 nurses/technicians, 78 dentists, 9 pharmacists, and 97 other HWs).

RESULTS: High proportion of HWs was using one surgery mask for two or more times or not using it at all when contacting patients who were self-isolated $(35.3 \%)$ or severe acute respiratory syndrome CoV (SARS-CoV)-2 positive (19.3\%). More than $90 \%$ of participants were using surgery masks and gloves every time or almost every time while working with patients who were self-isolated or SARS-CoV-2 positive. High frequency of participants reported: No isolation zones at the workplace $(61.2 \%)$, no triage of patients at the entrance $(33.4 \%)$, and not attended a training course about the correct usage of PPE $(72 \%)$.

CONCLUSION: The data obtained can be used in the creation of specific interventions in healthcare settings aimed at providing high-quality PPE through the development of a national healthcare strategy that can lead to the prevention of COVID-19 in HWs.

\section{Introduction}

The current coronavirus (CoV) disease (COVID)-19 pandemic has put immense pressure on the healthcare systems worldwide. Due to the eruptive spread of the disease, health workers (HWs) were placed on the frontline of the battle.

As crucial assets in every healthcare system, HWs are essential in maintaining adequate patient care and keeping the healthcare system functioning. During this public health emergency, the overburdened healthcare capacities, long working hours, staff shortages, and the immense psychological and physical pressure make HWs one of the most vulnerable groups of workers [1], [2], [3], [4].

The occupational risk to which the HWs are exposed is obvious. Examples exist from the early onset of the pandemic - the infection of around $3000 \mathrm{HWs}$ in the Hubei province, China and the death of Dr. Li Wenliang from Wuhan, who was one of the first who raised awareness for the severe acute respiratory syndrome CoV (SARS-CoV)-2 infection [5]. The latest updates report a proportion of $23 \%$ of infected HWs among confirmed cases from 15 countries in the EU/ EAA and the UK [6], [7]. In Republic of Macedonia, from all confirmed cases until now, 891 (5.6\%) COVID-19 cases and 6 deaths were reported among HWs [8].

The constant changes in the working environment, together with many unknown elements and uncertainties about the disease, the close contacts with contagious patients, the fear for themselves and their families, highly affects the wellbeing of the HWs. Furthermore, very often HWs without any previous expertise and training in dealing with patients with infectious diseases were recruited because of the shortage of qualified staff [2], [5].

All these factors emphasize the paramount need for ensuring safe workplaces for health-care providers. Three groups of preventive controls currently exist:

1. Administrative (e.g., early recognition of the disease, epidemiological surveillance, and control, providing effective training for $\mathrm{HWs}$ ) 
2.

Engineering controls (e.g., use of isolation rooms for patients, appropriate ventilation in the hospital settings), and

3. Availability of adequate personal protective equipment (PPE) - considered essential and effective measures that can prevent the transmission of the virus and reduce the risk that HWs are exposed to Park [4].

Having in mind that no form of PPE can completely protect from transmission, the combination of all three levels of control is crucial for the safety of HWs during the COVID-19 pandemic. Different forms of PPE exist, including surgical masks, respirators, gloves, goggles, glasses, face shields, gowns, and aprons. For every HW, the choice of proper PPE should match their individual risk level of exposure to COVID-19 and the possible ways of transmission [9], [10].

Three modes of transmission of COVID-19 are currently known: Through droplets (from coughing or sneezing), by direct contact (touching or being in contact with body parts contaminated with contagious material) - both originating from direct care with infected patients; and airborne mode (risk for aerosol exposure in HWs who are involved in aerosol-generating procedures [AGPs] [e.g., bronchoscopy and putting the patient on mechanical ventilation]) [11], [12].

Surgical masks, mainly used for patients' protection, are proven to protect HWs from droplet mode of transmission, as well, for utmost of $8 \mathrm{~h}$. They are considered the most common way of protection. For higher levels of protection, respirators are recommended. Based on their filter performance for particles with certain dimensions, three types exist $->0.3 \mu \mathrm{m}$ : Filtering facepiece (FFP)1 (>80\%), FFP2 $(>94 \%)$, and FFP3 (>99\%) [12].

According to WHO, HWs caring for COVID-19 patients should use surgical masks and eye protection (goggles or face shields) for droplet protection, longsleeved water-resistant gowns, and gloves for contact protection, and when the risk of aerosol exposure exists, the use of respirators (N95, FFP2, FFP3, or equivalent) and water-resistant gowns or aprons is highly recommended [9], [13].

Finally, to prevent exposure and transmission of COVID-19, HWs must correctly use the chosen PPE. Previous epidemic spreads, like the Ebola outbreak, showed that the inappropriate removal or doffing of PPE can lead to infection of HWs [16]. Taking into consideration the aforementioned experiences, providing active and practical training for correct use, doffing, and disposal of PPE, as well as proper assessment of the potential risks for infection at the workplace, are vital in the prevention strategy [14], [10].

In times when adequate COVID-19 vaccination and treatment are not available, putting HWs safety as a priority, by supplying adequate protection and emphasizing the importance of their role in the community, can establish stronger healthcare systems and better chances in fighting with the COVID-19 pandemic [3], [6].

\section{Objective}

The aim of the actual study was to assess the availability of PPE in HWs during COVID-19 outbreak, depending on the contacts of HWs with patients who were SARS-CoV-2 positive or self-isolated, and to propose activities toward improvement of detected shortcomings.

We also had an objective to determine: The frequency of daily changing of PPE, the satisfaction of HWs with the available PPE, the available triage of patients at the entrance of the health care facility, as well as available trainings for HWs about the usage of PPE.

\section{Methods}

The study was conducted during April-May 2020 after the announcement of the COVID-19 pandemic in Republic of Macedonia. Aself-administered questionnaire prefaced with an invitation letter and information about the study was sent to HWs in our country employing electronic communication through different platforms and social media. The invitations were sent on a weekly basis. For this purpose, we used all available social media, such as Linkedln and Twitter. The communications with professional organizations of HWs were used to increase the number of respondents. Participation in the study was voluntarily and anonymously.

We used an on-line questionnaire that was created following the $\mathrm{WHO}$ and $\mathrm{CDC}$ recommendations on the usage of PPE in HWs during an actual pandemic. The study instrument was developed through the collaboration of Institute of Occupational Health of RM, WHO CC, Skopje, Republic of Macedonia with the WHO CC for Occupational Health within the Faculty of Medicine, University in Zagreb, Croatia.

The survey instrument contained items about the availability of PPE (e.g., masks, respirators, gloves, goggles, face shields, scrubs, aprons, and gowns) in HWs during COVID-19 pandemic, the frequency of daily changing of PPE, the satisfaction of HWs with the available PPE, the available triage of patients at the entrance of the health-care facility, as well as available trainings for HCWs about the usage of PPE.

During survey development, we have validated the study instrument. Semi-structured interview was employed since the questionnaire used was not a standardized instrument. A small group of HWs $(n=10)$ was interviewed in order to modify the questionnaire and to assess the relevance, adequacy, 
and understandability of the proposed items by using a Likert scale and scores from 1 (not relevant at all, not adequate at all, or not understandable at all) to 5 (very relevant, very adequate, or very understandable).

Completed surveys were returned by $560 \mathrm{HWs}$ - 297 physicians (187 specialists, 110 residents), 79 nurses/technicians, 78 dentists, 9 pharmacists, and 97 other HWs. Participants were $69.5 \%$ female $(n=389)$. They had an average age of 40.3 (SD = 9.2) years and they worked in total for an average of $14.2(S D=9.4)$ years. Most of the participants have university degree ( $n=330,58.9 \%$ ), while others have finished high school ( $n=44,7.9 \%)$, have bachelor degree (3 years of university education) or similar ( $n=46,8.2 \%)$, or have obtained Master or PhD degree ( $n=84,15 \%)$ or other level of education $(n=56,10 \%)$.

\section{Results}

The participants, who were involved in the survey $(n=560)$, reported that during COVID-19 outbreak:

- Had contacts with patients who were selfisolated $(n=50,8.9 \%)$

- Had contacts with patients who were SARSCoV-2 positive $(n=45,8.1 \%)$

- Had contacts with both patients who were selfisolated and patients who were SARS-CoV-2 positive ( $n=117,20.9 \%$ ), or

- Had no contacts with neither self-isolated nor SARS-CoV-2 positive patients $(n=348$, $62.1 \%)$.

Table 1 shows the usage of masks and gloves in HWs during the COVID-19 outbreak, depending on the contacts of HWs with patients who were SARSCoV-2 positive or self-isolated.

Table 1: Different usage of masks and gloves in HWs during COVID-19 outbreak, depending on the contacts of HWs with patients who were SARS-CoV-2 positive or self-isolated

\begin{tabular}{lll}
\hline Variable & $\begin{array}{l}\text { Contacts with patients } \\
\text { who were self-isolated } \\
(\mathrm{n}=167) \mathrm{n}(\%)\end{array}$ & $\begin{array}{l}\text { Contacts with patients } \\
\text { who were SARS-CoV-2 } \\
\text { positive }(\mathrm{n}=166) \mathrm{n}(\%)\end{array}$ \\
\hline Use of one surgery mask & $108(64.7)$ & $134(80.7)$ \\
$\quad$ Once & $53(31.7)$ & $28(16.9)$ \\
Two or more times & $6(3.6)$ & $4(2.4)$ \\
Not using & $153(91.6)$ & $159(95.8)$ \\
Using surgery mask while working with patients & $2(1.2)$ \\
Every time & $8(4.8)$ & $1(0.6)$ \\
Almost every time & $3(1.8)$ & $1(0.6)$ \\
Sometimes & $1(0.6)$ & $3(1.8)$ \\
Almost never & $2(1.2)$ & \\
Never & $147(88.02)$ & $153(92.2)$ \\
Use of one pair of gloves & $15(8.98)$ & $12(7.2)$ \\
Once & $5(3)$ & $1(0.6)$ \\
Two or more times & $149(89.2)$ & $158(95.2)$ \\
Not using & $10(6)$ & $4(2.4)$ \\
Using gloves while working with & patients & $2(1.2)$ \\
Every time & $4(2.4)$ & $1(0.6)$ \\
Almost every time & $3(1.8)$ & $1(0.6)$ \\
Sometimes & $1(0.6)$ & \\
Almost never & & \\
Never & & \\
\hline COVID: Coronavirus disease, HWs: Health workers, SARS-CoV: Severe acute respiratory syndrome \\
coronavirus.
\end{tabular}

Table 1 data demonstrate that a high proportion of HWs was using one surgery mask for two or more times or not using at all when contacting patients who were self-isolated $(35.3 \%)$ or patients who were SARS-CoV-2 positive (19.3\%). The frequencies of HWs using one pair of gloves for two or more times or not using at all when contacting patients who were selfisolated $(11.98 \%)$ or patients who were SARS-CoV-2 positive $(7.8 \%)$ were lower. However, more than $90 \%$ of participants were using surgery mask every time or almost every time while working with patients who were self-isolated (96.4\%) or who were SARS-CoV-2 positive (97\%) and using gloves every time or almost every time while working with patients who were selfisolated $(95.2 \%)$ or who were SARS-CoV-2 positive $(97.6 \%)$.

Table 2 shows the usage of goggles/face shields, scrubs/aprons/gowns in HWs during the COVID-19 outbreak while contacting patients who were SARS-CoV-2 positive.

Table 2: Different usage of goggles/face shields, scrubs/aprons/ gowns in HWs during COVID-19 outbreak while contacting patients who were SARS-CoV-2 positive

\begin{tabular}{ll}
\hline Variable & $\begin{array}{l}\text { Contacts with patients who were SARS-CoV-2 } \\
\text { positive }(\mathrm{n}=166) \mathrm{n}(\%)\end{array}$ \\
\hline Use of one goggle/face shield & \\
Once & $56(33.7)$ \\
Two or more times & $107(64.5)$ \\
Not using & $3(1.8)$ \\
Using goggle/face shield while working with patients \\
Every time & $144(86.7)$ \\
Almost every time & $16(9.6)$ \\
Sometimes & $4(2.4)$ \\
Almost never & $1(0.6)$ \\
Never & $1(0.6)$ \\
Use of one scrub/apron/gown & $100(60.2)$ \\
Once & $55(33.2)$ \\
Two or more times & $11(6.6)$ \\
Not using & $121(72.9)$ \\
Using scrub/apron/gown while working with patients \\
Every time & $17(10.2)$ \\
Almost every time & $11(6.6)$ \\
Sometimes & $4(2.4)$ \\
Almost never & $13(7.8)$ \\
Never &
\end{tabular}

Table 2 data show that a high proportion of $\mathrm{HWs}$ was using one goggle/face shield $(66.3 \%)$ or one scrub/apron/gown (39.8\%) for two or more times or not using at all when contacting patients who were SARSCoV-2 positive. High frequencies of participants were using goggle/face shield (96.3\%) and scrub/apron/ gown $(83.1 \%)$ every time or almost every time while working with patients who were SARS-CoV-2 positive.

The participants reported that while contacting patients who were SARS-CoV-2 positive $(n=166)$ have been using the following masks/respirators:

- $\quad$ N95 (Every time $39.8 \%$, almost every time $10.2 \%$, sometimes $13.3 \%$, almost never $3 \%$, never $4.8 \%$, and not available in the healthcare institution $28.9 \%$ )

- $\quad$ FFP2 (every time $21.7 \%$, almost every time $9.6 \%$, sometimes $13.3 \%$, almost never $3.6 \%$, never $10.8 \%$, and not available in the healthcare institution $41 \%$ ), or 
FFP3 (every time 14.5\%, almost every time $1.2 \%$, sometimes $9 \%$, almost never $2.4 \%$, never $19.9 \%$, and not available in the healthcare institution 53\%)

The above data are clearly demonstrating that N95, FFP2, and FFP3 masks/respirators were frequently not available in the healthcare institution (N95 - 28.9\%, FFP2 - 41\%, and FFP3 - 53\%) for work with patients who were SARS-CoV-2 positive HWs have reported that while working with patients who were SARS-CoV-2 positive ( $n=166)$, they used one mask/respirator in aerosols-producing procedures:

Once $-57.2 \%(n=95)$

Two or more times $-39.2 \%(n=65)$, and

Did not use masks/respirator - 3.6\% $(n=6)$.

It is shown that a high frequency of HWs $(42.8 \%)$ was using one mask/respirator for two or more times or not using at all in aerosols-producing procedures with patients who were SARS-CoV-2 positive.

In addition, HWs participating in the survey ( $\mathrm{n}=560$ ) have been answering on two questions that have been focused on their satisfaction with the availability and the quality of the PPE at their workplace. Likert scale (from $0=$ not satisfied at all to $10=$ totally satisfied) was used. Concerning their satisfaction with the availability of the PPE at their workplace, 176 (31.4\%) were promoters (satisfied), 118 (21.1\%) were passives (neutral), and $266(47.5 \%)$ were detractors (not satisfied). Graphical representation could be found in Figure 1.

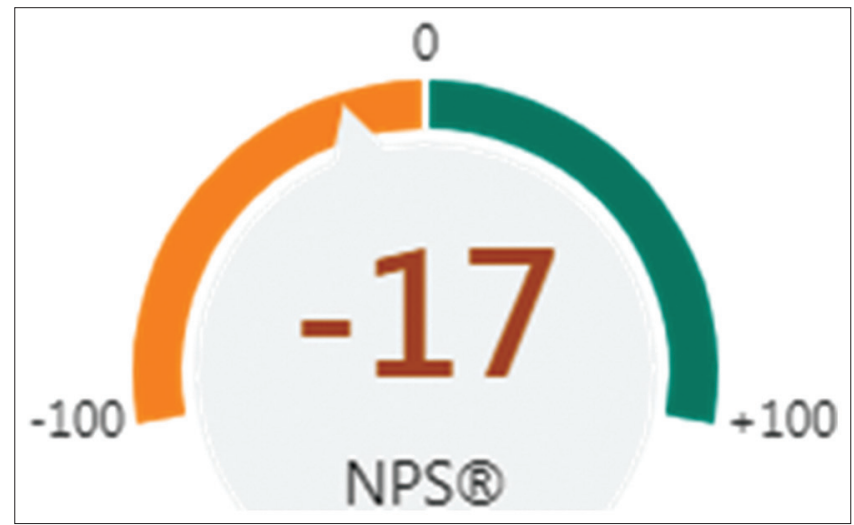

Figure 1: Satisfaction of HWs with the availability of the personal protective equipment at their workplace (in relative numbers)

The data in Figure 1 demonstrates that more HWs were not satisfied than satisfied with the availability of the PPE at the workplace. Concerning HWs' satisfaction with the quality of the PPE at their workplace, 168 (30\%) were promoters (satisfied), 124 (22.1\%) were passives (neutral), and 268 (47.9\%) were detractors (not satisfied). Graphical representation could be found in Figure 2.

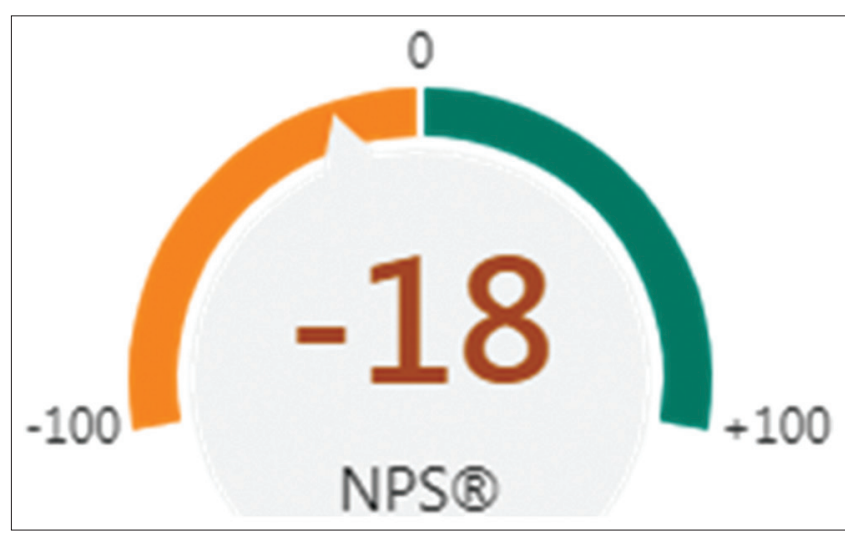

Figure 2: Satisfaction of HWs with the quality of the personal protective equipment at their workplace (in relative numbers)

The data in Figure 2 show that more HWs were not satisfied than satisfied with the quality of the PPE at the workplace. Overall, participants $(n=560)$ reported that during the working hours, they were using one mask:

- $\quad<4 \mathrm{~h}$ and then using another one - 234 (41.8\%),

- $\quad$ Longer than $4 \mathrm{~h}-297$ (53\%), or

- $\quad$ Not using mask - 29 (5.2\%).

The above data are clearly demonstrating that a high frequency of HWs (58.2\%) was using one mask longer than $4 \mathrm{~h}$ or not using mask at all. Concerning the organization of the working space into isolation zones (e.g., "Contaminated," "Potentially contaminated," and "Clean zone") aimed at reducing the spread of SARSCoV-2, 342 (61.1\%) study participants answered that there are no isolation zones in their health care facility. Triage of patients at the entrance of the health care facility was not reported by $187(33.4 \%)$ of evaluated HWs. Of all 560 participants, only 157 (28\%) reported that they have attended a training course about the correct usage of PPE. Finally, 144 (25.7\%) HWs did not know what to do after unwanted contact with blood or other secretions from a COVID-19 patient.

It is demonstrated that high frequency of participants reported: No isolation zones at the workplace $(61.2 \%)$, no triage of patients at the entrance $(33.4 \%)$, not attended a training course about the correct usage of PPE (72\%), and did not know what to do after unwanted contact with blood or other secretions from a COVID-19 patient (25.7\%).

\section{Discussion}

Starting from December 2019, SARS-CoV-2 and COVID-19 became a global health threat [15]. Having in mind the community transmission from asymptomatic individuals, disease burden is expected to rise, resulting in an urgent need for front-line HWs 
in treating patients. Hence, their work requires close personal exposure to patients with SARS-CoV-2 frontline HWs are at high risk of infection, contributing to its further spreading [1]. It is estimated that HWs may account for $10-20 \%$ of all COVID-19 cases [16], [17].

Consistent use of PPE is important to reduce nosocomial transmission, at least based on experience with other respiratory viruses [18]. UK and USA guidelines recommend wearing the mask for $\mathrm{HW}$ s caring for people with COVID-19 [19], [20]. Global shortages of masks, respirators, face shields, and gowns, caused by surging demand and supply chain disruptions, however, have led to efforts to conserve PPE through extended use or reuse. Furthermore, disinfection protocols have been developed, for which scientific consensus on best practice is scarce [21], [22], [23]. Addressing the needs of front-line HWs during the COVID-19 pandemic is by default a high priority [16], [24]; nevertheless, data to inform such efforts are still insufficient.

The prospective observational cohort study conducted in the UK and the USA within the general community, including front-line HWs, using self-reported data from the COVID Symptom Study smartphone application [25], assessed the risk of COVID-19 by practice location. The results showed that compared with the risk for the general community, risk for front-line HWs was increased in all healthcare settings, but it was highest for those working in inpatient settings (adjusted HR 24.30, 95\% Cl 21.83-27.06) and nursing homes (adjusted HR 16.24, 95\% Cl 13.39-19.70). Furthermore, HWs in nursing homes most frequently (16.9\%) reported inadequate PPE, whereas inpatient providers reported reuse of PPE most often (23.7\%). Front-line HWs had a threefold increased risk of reporting a positive COVID-19 test and predicted COVID-19 infection, compared with the general community, even after exclusion of other risk factors. Among front-line HWs, both reuses of PPE or inadequate PPE were associated with an increased risk of COVID-19. Increased susceptibility to SARS-CoV-2 infection was evident even among those HWs reporting adequate PPE, although the highest risk of infection was registered in those caring for patients with COVID19 who reported inadequate PPE. The greatest risk, however, was noticed among frontline HWs who worked in inpatient settings (where providers most frequently reported PPE reuse) and nursing homes (where providers most frequently reported inadequate PPE).

Our study showed that a high proportion of HWs reported reusing surgery masks and goggles/ face shields or not using them at all when contacting patients who were self-isolated or SARS-CoV-2 positive. In addition, high frequency of HWs in the actual study reported reusing masks/respirators in aerosolsproducing procedures with patients who were SARSCoV-2 positive. It is also noteworthy that in this study, at the beginning of the COVID-19 outbreak, more HWs were not satisfied with the availability and quality of the PPE at the workplace.
The Lancet study [25] also provides evidence that sufficient availability of PPE, quality of PPE, or both usually reduce the risk of COVID-19. The participants included in the actual study reported that N95, FFP2, and FFP3 masks/respirators were frequently not available in the healthcare institution for work with patients who were SARS-CoV-2 positive. However, the reuse of PPE or inadequate PPE might confer comparably increased risk, which is in accordance with findings from one of the first studies to specifically investigate PPE reuse [26]. The greater risk associated with PPE reuse could be related to either self-contamination during repeated application and removal of PPE or breakdown of materials from extended wear. Of note, during the period of this study, disinfection protocols before PPE reuse were not widely available [13], [21]. An assessment of the PPE supply chain and equitable access to PPE should be a part of the deliberate and informed decision making about resource allocation.

In addition, even with adequate PPE, HWs who cared for COVID-19 patients remained at increased risk, stressing the importance of not only ensuring quality and availability of used PPE but also other aspects of its appropriate use and removal in practice. Furthermore, the obtained data underline the possibility for community spread of the infection by HWs, particularly when asymptomatic or mildly symptomatic, and urge to increase testing to decrease hospital-based transmission [1]. One fact that is important is a significant difference in risk for HWs in the UK compared with the USA, which could be attributable to country-specific or region-specific variation in density of population, socioeconomic circumstances, overall availability and/ or quality of PPE, and type of healthcare settings. However, the study also reported that HWs in the UK were at higher risk of a positive test and also at greater risk of developing COVID-19 symptoms, which is not related to access to testing. The higher risk which is noted in UK could be associated with a higher infection rate due to differences in the quality and appropriate use of PPE [27] or differences in PPE use for HWs and the general population [28], [29].

The Pakistan study dealing with the preparedness of the healthcare personnel against the COVID-19 outbreak showed that there was a significant improvement in their knowledge about correct methods to make use of PPE which can afterward minimize their chances of getting infected [9]. Having in mind that PPE and testing kits are mostly in shortage in Pakistan, better understanding on these measures will not only be able to make appropriate use of available resources but also reduce costs and the growing economic burden [30], [31]. Therefore, such interventions may and will facilitate local implementation of international guidance that may contribute to flattening the curve. Our study clearly demonstrated that only a third of examined HWs reported that they have attended a training course about the correct usage of PPE, while 
a quarter of participating HWs did not know what to do after unwanted contact with blood or other secretions from a COVID-19 patient.

Meanwhile, TV and media images of HWs show a large variety of PPE being used, in many cases being worn incorrectly and compromising its effectiveness. On the other hand, every cough and sneeze from infected patient results in a spray of droplets and aerosol containing virus particles. The subsequent effect of this aerosol emission depends primarily on the size of the droplets, larger ones either impact or fall onto surfaces, but smaller ones remain airborne for some extended time periods [32], especially when there is potential exposure from AGPs. In this case, the use of medical (surgical) masks is sufficient in the circumstances where COVID-19 patients are present [33].

Within these circumstances, the healthcare sector needs to be more innovative in seeking out "novel" interventions to prevent infection in HWs. PPE might be an effective control measure but should never be the prime control because it is dependent on the worker's knowledge and skills to use the equipment properly to control this workplace hazard.

It is necessary to make the systems for the protection of workers from infectious risks as efficient as can be. In general, three choices of respiratory protective equipment, suitable for use in health and social care settings, are available nowadays: Surgical masks and disposable FFP, respirators with a face shield, and reusable powered air-purifying respirators (PAPRs). The first two are now commonly used and rely on the wearer fitting the device as closely as possible to the face and mouth. Two relevant standards are available in Europe: FFP2 (nominally reduces exposure by at least 75\%) and FFP3 (with a nominal 95\% reduction in inhaled particles concentration). FFP respirators better fit to the face, being an important reason why they provide a better protection level compared to surgical masks. The research with fine dust suggests that wearing a surgical mask might on average reduce aerosol concentrations by $\sim 70 \%$, whereas FFP respirators should reduce concentrations inhaled by $>95 \%$, on average [34]. PAPRs, however, should provide a more consistent fit and a higher degree of protection (>99.9\% reduction in aerosol concentration inhaled) [35]. Brosseau [36] reports a precautionary approach to be provided for healthcare workers exposed to infectious aerosols, but also to receive training on the use of respirators with high protection factors, such as PAPRs. However, until obtaining effective control, the proposed hierarchy of provisional inhalation exposure control measures, able to balance the risk reduction with the availability of supplies is strongly recommended (healthcare workers where infected patients may be present: A visor and FFP3 respirator; healthcare workers in the vicinity of AGPs: Minimum FFP3 and visor, but preferably a PAPR) [37].

Findings of the actual study should be adopted and interpreted with caution as answering bias could rise because it is possible that more affected HWs tended to respond. Furthermore, we have to take into consideration that cross-sectional design is limited with regard to causality. Additional limitations also include the fact that the analyses were based on self-reporting from questionnaires. Future research has to be focused on the differences in the availability and usage of PPE in HWs during the COVID-19 outbreak according to certain demographic (gender, age, and education) and job (profile, tenure, and type of healthcare institution) characteristics.

At the end, we can conclude that we have found several deficiencies in the availability and inconsistencies in the use of PPE in healthcare settings at the beginning of COVID-19 pandemic. The current situation is not unique for our context, as many authors from different countries are reporting such issues. However, the data obtained can be used in the creation and implementation of specific interventions in healthcare settings aimed at providing high-quality PPE. Providing adequate workplace safety through a national healthcare strategy can lead to the prevention of COVID-19 in HWs and contribute positively to a higher quality of patient care.

\section{References}

1. Black JR, Bailey C, Przewrocka J, Dijkstra KK, Swanton C COVID-19: The case for health-care worker screening to prevent hospital transmission. Lancet. 2020;395(10244):141820. https://doi.org/10.1016/s0140-6736(20)30917-x

PMid:32305073

2. Xiong $Y$, Peng L. Focusing on health-care providers' experiences in the COVID-19 crisis. Lancet Global Health. 2020;8(6):e740-1. https://doi.org/10.1016/s2214-109x(20)30214-x PMid:32573442

3. Adams JG, Walls RM. Supporting the health care workforce during the COVID-19 global epidemic. JAMA. 2020;323(15):1439-40. https://doi.org/10.1001/jama.2020.3972 PMid:32163102

4. Park SH. Personal protective equipment for healthcare workers during the COVID-19 pandemic. Infect Chemother. 2020;52(2):165-82. https://doi.org/10.3947/ic.2020.52.2.165 PMid:32618146

5. Liu Q, Luo D, Haase JE, Guo Q, Wang XQ, Liu S, et al. The experiences of health-care providers during the COVID-19 crisis in China: A qualitative study. Lancet Global Health. 2020;8(6):E790-8. https://doi.org/10.1016/ s2214-109x(20)30204-7 PMid:32573443

6. Smith C. The structural vulnerability of healthcare workers during COVID-19: Observations on the social context of risk and the equitable distribution of resources. Soc Sci Med. 2020;258:113119. https://doi.org/10.1016/j. socscimed.2020.113119 PMid:32534301

7. European Center for Disease Control and Prevention. Coronavirus disease 2019 (COVID-19) in the EU/EEA and 
the UK-latest Update, 30 June 2020. Stockholm: European Center for Disease Control and Prevention; 2020. https://doi. org/10.2807/1560-7917.es.2020.25.8.2002271

8. Institute of Public Health of Republic of North Macedonia. Situation with covid-19 in the republic of North Macedonia for the Period 07.09-13.09.2020-latest Update, 16 September 2020. Skopje: Institute of Public Health of Republic of North Macedonia; 2020. https://doi.org/10.31410/eman.s.p.2020.93

9. Cook TM. Personal protective equipment during the coronavirus disease (COVID) 2019 pandemic-a narrative review. Anaesthesia. 2020;75(7):920-7. https://doi.org/10.1111/ anae. 15071

\section{PMid:32246849}

10. Phan LT, Maita D, Mortiz DC. Personal protective equipment doffing practices of healthcare workers. J Occup Environ Hyg. 2019;16(8):575-81. https://doi.org/10.1080/15459624.2019.162 8350

PMid:31291152

11. Sommerstein R, FuxCA, Vuichard-Gysin D,Abbas M, Marschall J, Balmelli C, et al. Risk of SARS-CoV-2 transmission by aerosols, the rational use of masks, and protection of healthcare workers from COVID-19. Antimicrob Resist Infect Control. 2020;9(1):1-8. https://doi.org/10.1186/s13756-020-00763-0

12. Lockhart SL, Duggan LV, Wax RS, Saad S, Grocott HP. Personal protective equipment (PPE) for both anesthesiologists and other airway managers: Principles and practice during the COVID19 pandemic. Can J Anaesth. 2020;67(8):1005-15. https://doi. org/10.1007/s12630-020-01673-w

PMid:32329014

13. World Health Organization. Rational Use of Personal Protective Equipment for Coronavirus Disease (COVID-19) and Considerations During Severe Shortages: Interim Guidance. Geneva: World Health Organization; 2020.

14. Kantor J. Behavioral considerations and impact on personal protective equipment use: Early lessons from the coronavirus (COVID-19) pandemic. J Am Acad Dermatol. 2020;82(5):10878. https://doi.org/10.1016/j.jaad.2020.03.013 PMid:32171806

15. Anderson RM, Heesterbeek $\mathrm{H}$, Klinkenberg D, Hollingsworth TD. How will country-based mitigation measures influence the course of the COVID-19 epidemic? Lancet. 2020;395(10228):931-4. https://doi.org/10.1016/s0140-6736(20)30567-5 PMid:32164834

16. CDC COVID-19 Response Team. Characteristics of health care personnel with COVID-19: United States, February 12-April 9, 2020. MMWR Morb Mortal Wkly Rep. 2020;69(15):477-81. https://doi.org/10.15585/mmwr.mm6915e6

17. Lazzerini M, Putoto G. COVID-19 in Italy: Momentous decisions and many uncertainties. Lancet Glob Health. 2020;8(5):e641-2. https://doi.org/10.1016/s2214-109x(20)30110-8 PMid:32199072

18. Verbeek JH, Rajamaki B, ljaz S, Mäkelä E, Neuvonen $\mathrm{K}$, Edmond $\mathrm{MB}$, et al. Personal protective equipment for preventing highly infectious diseases due to exposure to contaminated body fluids in healthcare staff. Cochrane Database Syst Rev. 2020;4:CD011621. https://doi.org/10.1002/14651858. cd011621.pub5 PMid:27093058

19. US Centers for Disease Control and Prevention, CDC. Interim Infection Prevention and Control Recommendations for Healthcare Personnel During the Coronavirus Disease 2019 (COVID-19) Pandemic. Atlanta, GA: US Centers for Disease Control and Prevention, CDC; 2020. https://doi.org/10.1093/ ofid/ofv131.60

20. Public Health England. COVID-19 Personal Protective Equipment (PPE): 5-summary of PPE Recommendations for Health and Social Care Workers. London: Public Health England; 2020. https://doi.org/10.1016/j.jemep.2020.100546

21. Fischer $\mathrm{R}$, Morris $\mathrm{DH}$, van Doremalen $\mathrm{N}$, Sarchette $\mathrm{S}$, Matson MJ, Bushmaker T, et al. Assessment of N95 respirator decontamination and re-use for SARS-CoV-2. MedRxiv. 2020;4:1-11. PMid:32511432

22. Schwartz A, Stiegel M, Greeson N, Vogel A, Thomann W, Brown M, et al. Decontamination and reuse of N95 respirators with hydrogen peroxide vapor to address worldwide personal protective equipment shortages during the SARS-CoV-2 (COVID-19) pandemic. Appl Biosaf. 2020;25:67-70. https://doi. org/10.1177/1535676020919932

23. Livingston E, Desai A, Berkwits M. Sourcing personal protective equipment during the COVID-19 pandemic. JAMA. 2020;323(19):1912-4. https://doi.org/10.1001/jama.2020.5317 PMid:32221579

24. The Lancet. COVID-19: Protecting health-care workers. Lancet. 2020;395(10998):922. https://doi.org/10.1016/ s0140-6736(20)30644-9

PMid:32199474

25. Nguyen LH, Drew DA, Graham MS, Joshi AD, Guo CG, Ma W, et al. Risk of COVID-19 among front-line health-care workers and the general community: A prospective cohort study. Lancet Public Health. 2020;5(9):e475-83.

PMid:32745512

26. Chou R, Dana T, Buckley DI, Selph S, Fu R, Totten AM. Epidemiology of and risk factors for coronavirus infection in health care workers: A living rapid review. Ann Intern Med. 2020;173(2):120-36. https://doi.org/10.7326/m20-1632 PMid:32369541

27. Kenber B, Lay K, Fisher L, Smith HL. Fifth of Frontline Doctors Complain of Unusable Coronavirus PPE. London: The Times;2020.

28. Thomas JP, Srinivasan A, Wickramarachchi CS, Dhesi PK Hung YM, Kamath AV. Evaluating the national PPE guidance for NHS healthcare workers during the COVID-19 pandemic. Clin Med. 2020;20(3):242-7. https://doi.org/10.7861/ clinmed.2020-0143 PMid:32357976

29. Cheng KK, Lam TH, Leung CC. Wearing face masks in the community during the COVID-19 pandemic: Altruism and solidarity. Lancet. 2020;[online first]. https://doi.org/10.1016/ s0140-6736(20)30918-1

30. Sethi BA, Sethi A, Ali S, Aamir HS. Impact of coronavirus disease (COVID-19) pandemic on health professionals. Pak J Med Sci. 2020;36(4):S6-11. https://doi.org/10.12669/pjms.36. covid19-s4.2779

PMid:32582306

31. Aljazeera. Pakistani Doctors Decry Lack of Supplies as Lockdown Looms; 2020. Available from: https://www.aljazeera. com/news/2020/03/pakistani-doctors-decry-lack-supplieslockdown-debate-rages-200323110940130.html. [Last accessed on 2020 Sep 11].

32. Redrow J, Mao S, Celik I, Posada JA, Feng ZG. Modeling the evaporation and dispersion of airborne sputum droplets expelled from a human cough. Build Environ. 2011;46(10):204251. https://doi.org/10.1016/j.buildenv.2011.04.011

33. World Health Organization. Advice on the Use of Masks in the Community, During Home Care, and in Health Care Settings in the Context of COVID-19. Geneva: World Health Organization; 2020.

34. Cherrie JW, Apsley A, Cowie H, Steinle S, Mueller W, Lin $C$, et al. Effectiveness of face masks used to protect Beijing residents against particulate air pollution. Occup 
Environ Med. 2018;75(6):446-52. https://doi.org/10.1136/ oemed-2017-104765

35. Park SH, Hwang SY, Lee G, Park JE, Kim T, Shin TG, et al. Are loose-fitting powered air-purifying respirators safe during chest compression? A simulation study. Am J Emerg Med. 2020; [article in press]. https://doi.org/10.1016/j.ajem.2020.03.054

36. Brosseau LM. Are powered air purifying respirators a solution for protecting healthcare workers from emerging aerosol-transmissible diseases? Ann Work Expo Health 2020;64(4):339-41. https://doi.org/10.1093/annweh/wxaa024

PMid:32154831

37. Cherrie JW, Loh M, Aitken RJ. Protecting healthcare workers from inhaled SARS-CoV-2 virus. Occup Med (Lond). 2020;70(5):335-7. https://doi.org/10.1093/occmed/kqaa077

PMid:32352523 